\title{
Driver/Vehicle Characteristics in Rear-End Precrash Scenarios Based on the General Estimates System (GES)
}

Christopher J. Wiacek and Wassim G. Najm

Volpe National Transportation Systems Center

Reprinted From: IV: Vehicle Navigation Systems and Advanced Controls

(SP-1428) 
The appearance of this ISSN code at the bottom of this page indicates SAE's consent that copies of the paper may be made for personal or internal use of specific clients. This consent is given on the condition, however, that the copier pay a $\$ 7.00$ per article copy fee through the Copyright Clearance Center, Inc. Operations Center, 222 Rosewood Drive, Danvers, MA 01923 for copying beyond that permitted by Sections 107 or 108 of the U.S. Copyright Law. This consent does not extend to other kinds of copying such as copying for general distribution, for advertising or promotional purposes, for creating new collective works, or for resale.

SAE routinely stocks printed papers for a period of three years following date of publication. Direct your orders to SAE Customer Sales and Satisfaction Department.

Quantity reprint rates can be obtained from the Customer Sales and Satisfaction Department.

To request permission to reprint a technical paper or permission to use copyrighted SAE publications in other works, contact the SAE Publications Group.

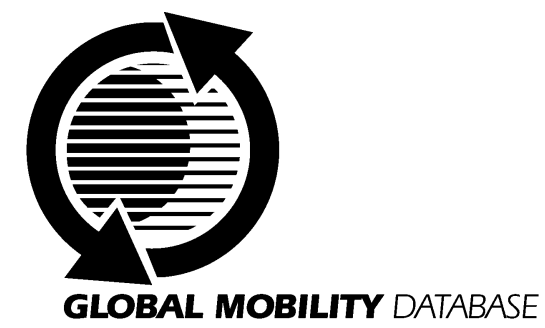

All SAE papers, standards, and selected books are abstracted and indexed in the Global Mobility Database

No part of this publication may be reproduced in any form, in an electronic retrieval system or otherwise, without the prior written permission of the publisher.

\section{ISSN 0148-7191}

Copyright 1999 Society of Automotive Engineers, Inc.

Positions and opinions advanced in this paper are those of the author(s) and not necessarily those of SAE. The author is solely responsible for the content of the paper. A process is available by which discussions will be printed with the paper if it is published in SAE Transactions. For permission to publish this paper in full or in part, contact the SAE Publications Group.

Persons wishing to submit papers to be considered for presentation or publication through SAE should send the manuscript or a 300 word abstract of a proposed manuscript to: Secretary, Engineering Meetings Board, SAE.

\section{Printed in USA}




\title{
Driver/Vehicle Characteristics in Rear-End Precrash Scenarios Based on the General Estimates System (GES)
}

\author{
Christopher J. Wiacek and Wassim G. Najm \\ Volpe National Transportation Systems Center
}

Copyright (C) 1999 Society of Automotive Engineers, Inc.

\begin{abstract}
Dynamically-distinct precrash scenarios in rear-end collisions were identified in a recent study conducted by the Volpe National Transportation Systems Center, of the United States Department of Transportation, Research and Special Programs Administration, in conjunction with the National Highway Traffic Safety Administration (NHTSA) using NHTSA's General Estimates System (GES) crash database from 1992 through 1996. Precrash scenarios represent vehicle dynamics immediately prior to a collision. This paper provides a statistical description of the five most frequently-occurring rear-end precrash scenarios in terms of vehicle and driver characteristics, using the 1996 GES database. The statistics presented in this paper encompass driver characteristics of the following vehicle including avoidance maneuver attempted before impact, crash contributing factors, driver age, and gender; vehicle body types involved in these rear-end precrash scenarios; and initial travel speeds of the following vehicle under various posted speed limits. The results of this study will be useful in estimating the safety benefits of advanced-technology rear-end collision avoidance systems in terms of both crash number reduction and severity mitigation.
\end{abstract}

\section{INTRODUCTION}

The rear-end crash type has the highest frequency of occurrence among all vehicular crashes, which accounts for approximately one quarter of all police-reported crashes [1]. Vehicle-based rear-end collision warning systems and adaptive cruise control systems have the potential to alleviate the rear-end crash problem. The potential safety benefits of such systems can be best assessed by estimating the effectiveness of these systems in different rear-end precrash scenarios, taking into consideration crash statistics associated with each of these scenarios. In a recent study, dynamically-distinct rear-end precrash scenarios have been identified using the National Highway Traffic Safety Administration's (NHTSA) General Estimates System (GES) crash database [2]. This database provides the largest nationally- representative crash sample available, which includes about forty-eight thousand police-reported crashes annually. Moreover, the GES database enables the identification of precrash scenarios based on vehicle dynamics and critical events that occur immediately prior to a collision in conjunction with roadway geometry [3].

This paper provides a statistical description of major rearend precrash scenarios based on approximately 12,000 rear-end crash cases in the 1996 GES database. Specifically, this paper presents statistics on drivers in the following vehicle and on body types of vehicles involved in these rear-end precrash scenarios. The Vehicle/Driver File as well as the Person File of the GES database were used to identify the characteristics of both the following vehicle driver and vehicles involved. Driver characteristics include driver response to critical events, crash contributing factors, driver age and gender. Vehicle characteristics encompass body types of both striking and struck vehicles and following vehicle travel speed prior to the driver's realization of an impending danger. It should be noted that crash statistics on maximum injury severity, roadway surface condition, posted speed limit, and light and atmospheric conditions can be found in Reference [2] for the five most frequently-occurring rearend precrash scenarios. Finally, the results of this study will be useful in estimating the safety benefits of advanced-technology rear-end collision avoidance systems in terms of both crash number reduction and severity mitigation.

\section{PRECRASH SCENARIO IDENTIFICATION}

Rear-end precrash scenarios were identified by examining combinations of two precrash variables in conjunction with the Accident Type and Vehicle Role variables, all in the GES Vehicle/Driver File, along with the Roadway Alignment and Traffic Control Device variables in the GES Accident File. The first precrash variable, Movement Prior to Critical Event, describes a vehicle's activity prior to the driver's realization of an impending critical event or danger. This variable discerns vehicle maneuvers, such as passing or turning, and dynamic states such as 
stopped or decelerating. Our analysis of rear-end crashes listed the lead vehicle as "decelerating" to a stop shortly before impact if its dynamic state was coded as Stopped In Traffic Lane on a straight road either due to a traffic control device or in order to make a turn. This assumption was based on a previous study conducted under an NHTSA-sponsored project to develop performance guidelines for advanced-technology rear-end crash countermeasure systems [4]. It was assumed that a forward-looking sensor on the following vehicle would have the lead vehicle within plain view while decelerating to a stop on a straight road. If the same conditions occurred on a curved road, the lead vehicle was listed as "stopped" shortly before impact, as initially coded in the GES, based on the assumption that a forward-looking sensor would not have the lead vehicle in view until it came to a complete stop. The second precrash variable, Critical Event, identifies the critical event which made the crash imminent (i.e., something occurred which made the collision possible). This variable does not refer to culpability. The Accident Type variable contains a category on same trafficway/same direction, rear-end crashes which is further defined by various crash configurations. The Vehicle Role variable indicates vehicle role in single or multi-vehicle crashes, such as striking or struck. The Roadway Alignment variable points to whether the road is straight or curved. Finally, the Traffic Control Device variable indicates the type and whether or not a traffic control device was present at the crash site.

A set of about twenty distinct rear-end precrash scenarios was identified by examining relevant GES cases that were coded in the database from 1992 through 1996. This set accounted for an average of 98 percent of all rear-end crashes over this five-year period. Table 1 defines and ranks the top five rear-end precrash scenarios in a descending order based on the weighted relative frequency of occurrence. These five precrash scenarios comprise an average of about 89 percent of all rear-end crashes.

\section{DRIVER CHARACTERISTICS}

The characteristics of drivers involved in rear-end collisions are obtained from the Vehicle/Driver and Person Files in the GES database. Such characteristics include avoidance maneuver attempted in response to the imminent crash, driver factors contributing to the crash, driver age, and gender. The statistics on major driver characteristics of the following vehicle are presented in this paper for the top five rear-end precrash scenarios using the 1996 GES database. Next, driver characteristics are statistically described in terms of avoidance maneuver attempted, contributing factors, driver age and gender, respectively.
Table 1. Definition and Relative Frequency of Top Five Rear-End Precrash Scenarios (Based on 1992- 1996 GES) [2]

\begin{tabular}{|c|c|c|}
\hline No. & Scenario Definition & $\begin{array}{c}\text { Relative }^{\star} \\
\text { Frequency, \% }^{2}\end{array}$ \\
\hline 1 & $\begin{array}{l}\text { Both following and lead vehicles are } \\
\text { traveling at constant speed on a straight } \\
\text { road and lead vehicle then decelerates. }\end{array}$ & 37.0 \\
\hline 2 & $\begin{array}{l}\text { Following vehicle is traveling at constant } \\
\text { speed on a straight road and encounters } \\
\text { a lead vehicle stopped in traffic lane } \\
\text { ahead. }\end{array}$ & 30.2 \\
\hline 3 & $\begin{array}{l}\text { Following vehicle is traveling at constant } \\
\text { speed on a straight road and encounters } \\
\text { a lead vehicle traveling at a constant, } \\
\text { lower speed ahead. }\end{array}$ & 14.1 \\
\hline 4 & $\begin{array}{l}\text { Both following and lead vehicles are } \\
\text { decelerating on a straight road and lead } \\
\text { vehicle then decelerates at a higher rate. }\end{array}$ & 4.5 \\
\hline 5 & $\begin{array}{l}\text { Following vehicle is traveling at constant } \\
\text { speed on a curved road and encounters } \\
\text { a lead vehicle stopped in traffic lane } \\
\text { ahead. }\end{array}$ & 3.0 \\
\hline & Sum & 88.8 \\
\hline
\end{tabular}
through 1996.

AVOIDANCE MANEUVER ATTEMPTED - The statistics on the avoidance maneuver attempted by the driver in the following vehicle are obtained from the Corrective Action Attempted variable in the Vehicle/ Driver File of the 1996 GES database. This variable describes the actions taken by the driver in response to the impending danger. Table 2 presents the statistical distribution of failed driver attempts to avoid a rear-end crash in the top five precrash scenarios. As seen in Table 2, there was no action attempted by the following driver in over 78 percent of the cases in rear-end precrash scenarios 1, 2, 3, and 5. This percentage is lower in precrash scenario 4 at about 69 percent. Driver inattention could explain the lack of corrective action taken by the driver in the following vehicle, which was estimated to cause about 76 percent of all rear-end collisions [1]. In case of corrective action taken, braking was the most likely response to the rearend crash threat among the top five scenarios. Such information might be useful in the development of driver decision models in computer simulation of rear-end precrash scenarios.

Table 2. Percent Distribution of Attempted Avoidance Maneuvers (Based on 1996 GES)

\begin{tabular}{|c|c|c|c|c|c|}
\hline Action Attempted & No. 1 & No. 2 & No. 3 & No. 4 & No. 5 \\
\hline No Action & 81.4 & 78.4 & 83.8 & 68.6 & 86.2 \\
\hline Braked & 12.2 & 15.5 & 8.1 & 25.7 & 11.1 \\
\hline Steered & 1.1 & 2.2 & 1.7 & 1.4 & 0.7 \\
\hline Braked \& Steered & 0.5 & 1.0 & 0.4 & 1.4 & 0.2 \\
\hline Accelerated & 0.1 & 0.0 & 0.0 & 0.0 & 0.0 \\
\hline Other/No Details & 0.3 & 0.1 & 0.4 & 0.1 & 0.0 \\
\hline Unknown & 4.5 & 2.8 & 5.6 & 2.8 & 1.8 \\
\hline \hline *: Sum & $100.1^{*}$ & 100.0 & 100.0 & 100.0 & 100.0 \\
\hline Rounding Error & \multicolumn{5}{|l}{} \\
\hline
\end{tabular}


DRIVER CONTRIBUTING FACTORS - The GES database contains a number of variables referring to circumstances, conditions, and events that may have contributed to the crash. From the GES Vehicle/Driver File, this study examined the variables Driver Distracted $B y$, Driver's Vision Obscured By, Driver Drinking in Vehicle, and Violations Charged. The variable Driver Distracted By attempts to capture distractions which may have influenced driver performance while the variable Driver's Vision Obscured By identifies visual circumstances which may have contributed to the cause of the crash. In addition, the variable Person's Physical Impairment from the GES Person File was also examined in this study.

Table 3 presents the statistics on contributing factors of the driver in the following vehicle for each of the top five rear-end precrash scenarios. Among the five scenarios, the driver was distracted more in precrash scenarios 2 and 3 at about 7 percent and 8 percent of their cases, respectively. Internal distraction was mostly cited in distraction cases. Audible or haptic warnings issued by a rear-end collision avoidance system could be effective in cases where a driver was distracted by alerting the driver to the impending danger. Table 3 also shows that driver's vision was obscured in about 2 percent of the cases in scenarios 2, 3, 4, and 5 . Reflected glare and bright sunlight were the dominant factors in rear-end precrash scenarios 2, 3, and 5; while rain, snow, or fog was mostly cited in vision obstruction cases in scenario 4 . The forward-looking sensor(s) of a rear-end collision avoidance system would have to detect the lead vehicle and warn the driver when appropriate in cases where the driver's visibility is compromised. Alcohol use by the driver of the following vehicle was reported in about 5 percent and 6 percent of the cases in scenarios 1 and 3, respectively. This statistic is approximately 3 percent in the remaining three scenarios. It should be noted that alcohol use by the driver is generally much higher in fatal crashes.

According to Table 3, the driver of the following vehicle was charged with a violation in as high as 51 percent of the cases. Violations charged to the driver included alcohol or drugs, speeding, alcohol or drugs and speeding, reckless driving, failure to yield right-of-way, hit and run, revoked license, running a traffic signal or stop sign, and other violations/no details. Unfortunately, the "other violation/no details" codes were commonly cited under the variable Violations Charged in the GES. Of the known violations, speeding was the dominant charge. Finally, the driver was physically impaired in about 2 percent of the cases in scenario 3, the highest among the five rear-end precrash scenarios. Drowsy, ill, or blackout was mostly indicated in these cases. Generally, rear-end collision warning systems would not be effective in cases involving drivers drinking/drunk in the vehicle or physically-impaired.
Table 3. Percent Distribution of Contributing Factors (Based on 1996 GES)

\begin{tabular}{|c|c|c|c|c|c|}
\hline Driver Factor & No. 1 & No. 2 & No. 3 & No. 4 & No. 5 \\
\hline Distracted & 4.6 & 7.1 & 7.8 & 1.7 & 4.2 \\
\hline Vision Obstructed & 0.7 & 1.6 & 1.5 & 1.5 & 2.1 \\
\hline Drinking Alcohol & 4.6 & 2.6 & 5.7 & 2.6 & 2.8 \\
\hline Violation Charged & 48.5 & 51.0 & 48.3 & 26.9 & 36.1 \\
\hline Physically Impaired & 0.8 & 0.7 & 1.7 & 0.2 & 0.9 \\
\hline
\end{tabular}

Note: Driver factor statistics are not mutually exclusive and numbers in columns do not add up to 100 .

DRIVER AGE AND GENDER - The Age and Sex variables in the GES Person File were used to categorize both age and gender of following vehicle drivers involved in the top five rear-end precrash scenarios. Tables 4 and 5 present, respectively, the percent distributions of driver age and gender in each of the five scenarios. Drivers between the age of 16 and 24 years are over-represented in all five scenarios at approximately 30 percent of rear-end collision cases, given that this age category constitutes about 21 percent of all licensed drivers [5]. Conversely, drivers over 64 years of age are under-represented at about 6 percent of rear-end collision cases, given that this age category accounts for about 13 percent of all licensed drivers.

Table 4. Percent Distribution of Following Driver Age (Based on 1996 GES)

\begin{tabular}{|c|c|c|c|c|c|}
\hline Driver Age & No. 1 & No. 2 & No. 3 & No. 4 & No. 5 \\
\hline $16-24$ years & 30.9 & 35.0 & 30.5 & 31.6 & 29.9 \\
\hline $25-64$ years & 63.9 & 58.4 & 64.3 & 61.7 & 65.1 \\
\hline $65+$ years & 5.2 & 6.7 & 5.2 & 6.7 & 5.0 \\
\hline \hline Sum & 100.0 & $100.1^{*}$ & 100.0 & 100.0 & 100.0 \\
\hline & *: Rounding Error
\end{tabular}

Table 5 shows that male drivers are slightly over-represented in rear-end collisions at about 60 percent, considering that licensed male drivers constitute about 53 percent of the driving population [5].

Table 5. Percent Distribution of Following Driver Gender (Based on 1996 GES)

\begin{tabular}{|c|c|c|c|c|c|}
\hline Driver Gender & No. 1 & No. 2 & No. 3 & No. 4 & No. 5 \\
\hline Male & 62.5 & 61.2 & 65.4 & 55.9 & 59.9 \\
\hline Female & 37.5 & 38.8 & 34.6 & 44.1 & 40.1 \\
\hline \hline Sum & 100.0 & 100.0 & 100.0 & 100.0 & 100.0 \\
\hline
\end{tabular}




\section{VEHICLE CHARACTERISTICS}

The statistical characteristics of vehicles involved in rearend collisions, in terms of body type and travel speed, can be obtained from the GES Vehicle/Driver File. Specifically, this paper presents statistics on body type of both striking and struck vehicles and on travel speed of the following vehicle for each of the top five rear-end precrash scenarios.

VEHICLE BODY TYPE - The variable Body Type indicates the type of the vehicle involved in the crash, including automobiles, utility vehicles, van-based light trucks, light conventional trucks, buses, medium or heavy vehicles, motored cycles, and 'other' vehicles such as snowmobiles, farm equipment, street sweepers, etc. Table 6 shows the percent distribution of vehicle types involved in rear-end collisions for both striking and struck vehicles. Moreover, the statistics are presented for each of the top five rear-end precrash scenarios, defined in Table 1, under four vehicle categories. The "light vehicle" category consists of automobiles, light trucks, utility vehicles, and vans. The "truck" category encompasses both medium and heavy trucks. The "other" category includes motored cycles and 'other' vehicles.

Table 6. PercentDistribution of Vehicle Types Involved (Based on 1996 GES)

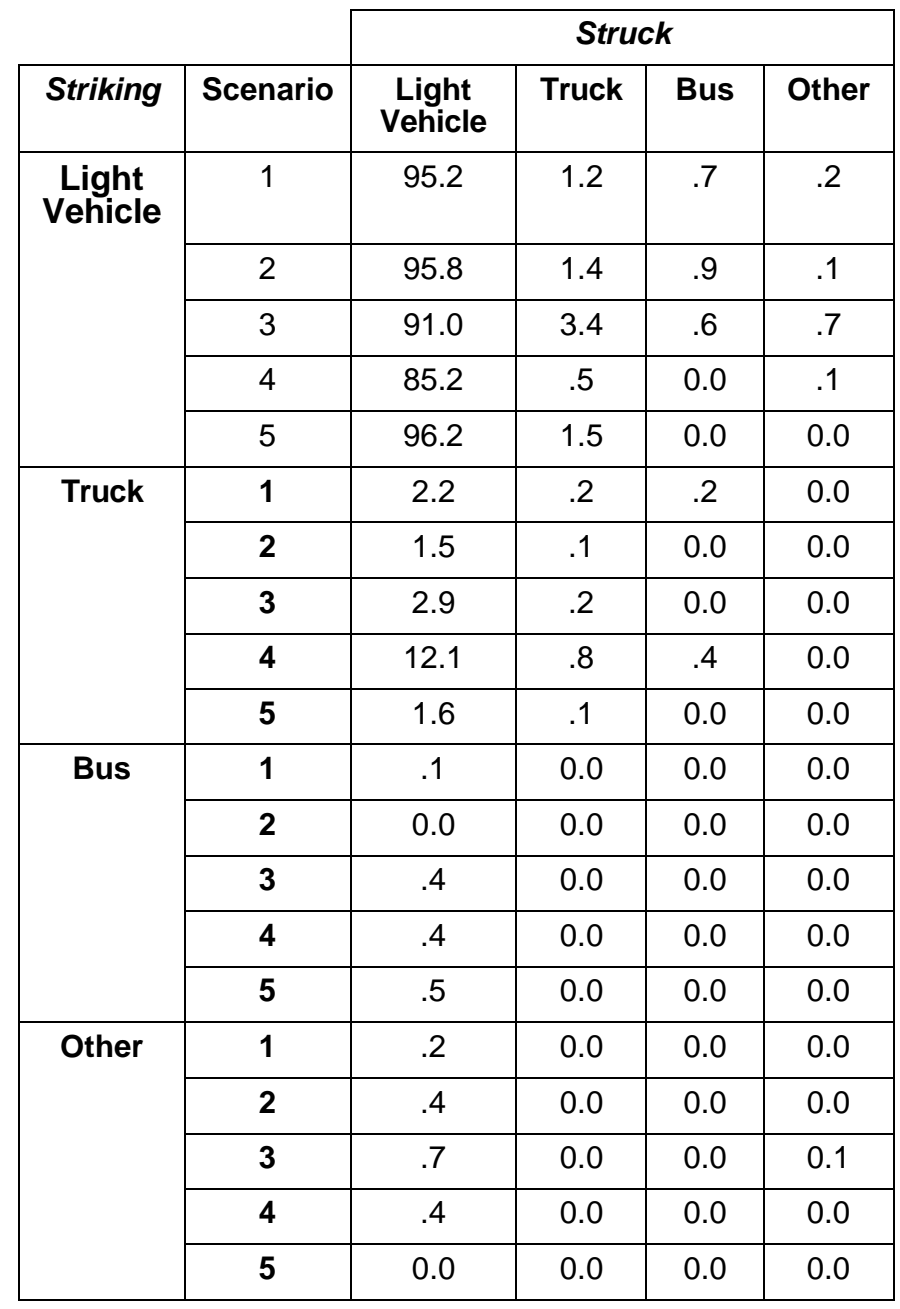

As seen in Table 6, a light vehicle struck another light vehicle in over 90 percent of rear-end collisions classified under precrash scenarios $1,2,3$, and 5 . This statistic is lower for precrash scenario 4 at about 85 percent. It should be noted that light vehicles accounted for about 95.4 percent of the 1995 vehicle fleet in the United States; trucks, buses, and "other" vehicles comprised respectively $2.4,0.3$, and 1.9 percent of the 1995 vehicle fleet [6]. In rear-end precrash scenario 4 (Where both following and lead vehicles were initially decelerating before the critical event), a truck struck a light vehicle in 12.1 percent of the cases, compared to only 3 percent or below in the other scenarios. This statistic is exceptional given that a light vehicle struck a truck in only 0.5 percent of the cases in rear-end precrash scenario 4 . Among the five rear-end precrash scenarios, the truck is most likely to hit a lead vehicle in rear-end precrash scenario 4 (13.3 percent of scenario cases).

FOLLOWING VEHICLE TRAVEL SPEED - Statistics on travel speed of the following vehicle were obtained from the Travel Speed variable, which indicates the actual travel speed of the vehicle in miles per hour (MPH) prior to the driver's realization of an impending danger. This paper presents statistical distributions of following vehicle travel speed with respect to various posted speed limits (Speed Limit variable in the GES Accident File). This was an initial attempt to quantify the relationship between actual vehicle speed and certain posted speed limit. Figure 1 illustrates the distribution of actual speed data with respect to 35,45 , and $55 \mathrm{MPH}$ posted speed limits. The data presented in Figure 1 were an aggregate of the 'known' data on vehicle speeds for the top five rear-end precrash scenarios. It should be noted that about 70 percent of the actual speed data in the GES database were coded as unknown. The average vehicle speed was about 23,27 , and $39 \mathrm{MPH}$ respectively in the 35,45 , and 55 posted speed limit zones. These results show that a significant majority of rear-end collisions occur below the posted speed limit. This finding might be attributed to congested traffic conditions that restrict drivers from maintaining the posted speed.

\section{CONCLUSION}

This paper presented a statistical description of driver and vehicle characteristics for the five most frequentlyoccurring precrash scenarios in rear-end collisions, based on the 1996 GES database. Driver characteristics were described for the driver of the following vehicle in terms of failed avoidance maneuver attempts, factors contributing to the crash, age, and gender. The data showed that the driver did not attempt any avoidance maneuver in over 78 percent of the cases. Braking was the most likely avoidance action taken when the driver reacted to the impending threat. Moreover, the driver was charged with a violation in as high as 51 percent of the cases. In addition, drivers between the ages of 16 and 24 were over-represented in rear-end collisions at about 30 percent of all cases. Vehicle characteristics 
were obtained for body type of all vehicles involved and actual travel speed of the following vehicle. A light vehicle struck another light vehicle in over 90 percent of rearend collisions. Also, trucks were most likely to hit another vehicle in rear-end precrash scenario where both vehicles were initially decelerating. Finally, the available known data showed that the following vehicle was traveling at an average speed below the posted speed limit before colliding with a lead vehicle.

\section{DISCLAIMER}

The conclusions and opinions expressed in this paper are those of the authors and do not represent the position of the U.S. Department of Transportation, with respect to the matters discussed.

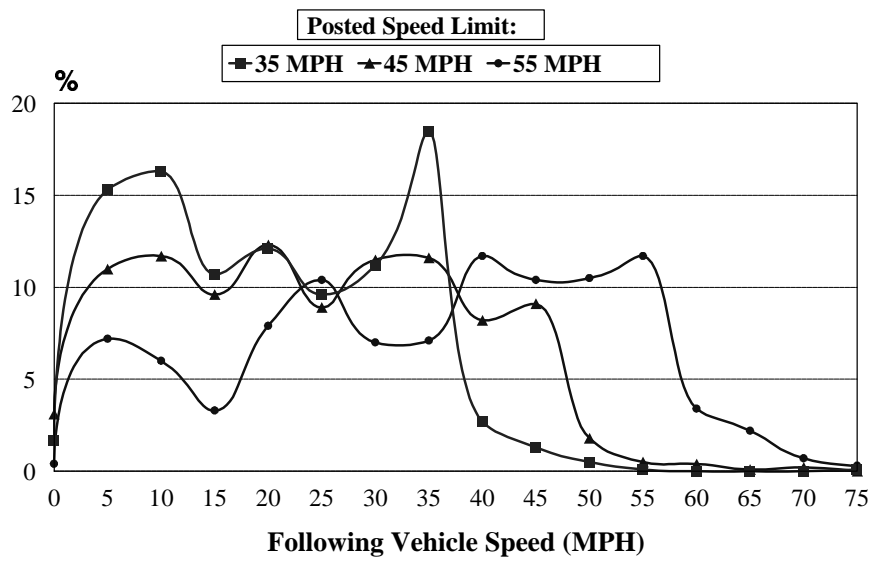

Figure 1. Distribution of Following Vehicle Speed vs. Posted Speed Limit (Based on 1996 GES)

\section{REFERENCES}

1. Najm, W., Mironer, M., Koziol, J.,Wang, J., \& Knipling, R., Synthesis Report: Examination of Target Vehicular Crashes and Potential ITS Countermeasures, DOT HS 808 263, June 1995.

2. Najm, W., Wiacek, C., Burgett, A., Identification of Precrash Scenarios for Estimating the Safety Benefits of Rear-End Collision Avoidance Systems, $5^{\text {th }}$ ITS World Congress, Seoul, Korea October 1998.

3. U.S. Department of Transportation, National Highway Traffic Safety Administration, National Accident Sampling General Estimates System (GES) - Users's Manual - 1995 File, National Accident Sampling Systems General Estimates System Technical Note, DOT HS 807796.

4. Wilson, T., IVHS Countermeasures for Rear-End Collisions, Task 1, Volume IV: 1992 NASS CDS Case Analysis, Interim Report, DOT HS 808 564, February 1994.

5. Teets, M.K., Editor, Highway Statistics Summary to 1995, United States Department of Transportation, Federal Highway Administration, FHWA-PL-97-009, July 1997.

6. Davis, S.C., Transportation Energy Data Book: Edition 17, Oak Ridge National Laboratory, ORNL-6919, Oak Ridge, TN, August 1997. 